\title{
A Policy Strategy Evaluation for Covid-19 Pandemic in the City of Surabaya Using Vensim Ventana Dynamic System Simulation
}

\author{
Jesselyn Clarissa Hadiwibowo \\ Industrial Engineering Department \\ Petra Christian University \\ Surabaya, Indonesia \\ c13170031@john.petra.ac.id \\ Karina Agustin \\ Industrial Engineering Department \\ Petra Christian University \\ Surabaya, Indonesia \\ karinaagustin@petra.ac.id
}

\author{
Siana Halim \\ Industrial Engineering Department \\ Petra Christian University \\ Surabaya, Indonesia \\ halim@petra.ac.id \\ Iwan Halim Sahputra \\ Industrial Engineering Department \\ Petra Christian University \\ Surabaya, Indonesia \\ iwanh@petra.ac.id
}

\author{
Bernardo Nugroho Yahya \\ Industrial and Management \\ Engineering Department \\ Hankuk University of Foreign Studies \\ Global Campus \\ Seoul, South Korea \\ bernardo@hufs.ac.kr
}

\begin{abstract}
The global Covid-19 pandemic has been a considerable concern worldwide. In Surabaya city, the government has taken particular measures to establish appropriate policies to overcome the Covid-19 pandemic. However, there has been no precise measure to verify the effectiveness of the policy in the future. This research aims to evaluate the Surabaya Government policy scenario using a dynamic system-based simulation with Vensim Ventana software. The initial model was designed with adopting the Covid-19 model made by Tom Fiddaman, Ventana System in 2020 adjusted to real conditions in Surabaya. The simulation results obtained from the initial validated model estimate that the Covid-19 pandemic would end on May 5, 2021, with total infected 15,876 people. The model was then developed by simulating several policy scenarios: herd immunity, convalescent plasma therapy, and swab test to predict policy's impact. The best-case scenario is gained by combining the convalescent plasma therapy policy and increasing the number of swab tests at Labkesda to 4,000 samples per day. The simulation results' prediction shows the pandemic will end 52 days earlier, with the percentage of the infected population $23.77 \%$ smaller than the initial model. It can be concluded that the government's strategy of collaborating the two policies is effective to overcome the pandemic in Surabaya. Nevertheless, the implementation of policies to overcome this pandemic success with contributions from all elements of society.
\end{abstract}

Keywords-Covid-19 pandemic in Surabaya City, dynamic system simulation, policy scenario

\section{INTRODUCTION}

Covid-19 is a disease that initially broke out in Wuhan, China, at the end of 2019. Furthermore, Covid-19 was designated by the World Health Organization (WHO) as a global pandemic on Wednesday, March $11^{\text {th }}, 2020$, based on reports of 118,000 positive cases spread across 114 countries in this world. Based on data released in Indonesia (initial case - mid-July 2020), East Java Province is the province with the largest contributor to positive cases in Indonesia. On the other hand, it turns out that Surabaya is the city with the highest positive confirmation in East Java Province [1].

Surabaya is the second-largest city in Indonesia and has a high level of population mobility. Therefore, controlling population mobility related to the Covid-19 pandemic is very necessary. The government has set various policies until mid-July 2020 , but the results show that there is still a high rate of increase and the spread of positive cases in Surabaya. Therefore there is a need to build a model to evaluate the impact of the policies on the virus's spread.

System dynamic modeling has been employed to study infectious diseases, such as human immunodeficiency virus (HIV) transmission [2, 3]. This approach has also been applied to investigate the effects of the disease on Indonesia's economy [4] and labor migrants' policy on the country's economic growth affected by the Covid-19 pandemic [5]. Moreover, dynamic system modeling has been simulated to explain social measures' effectiveness against Covid-19 outbreaks in selected Japanese regions [6] and trace the spread of COVID-19 in Italy, India, South Korea, and Iran [7]. The other study proposed a susceptible-exposedinfected-removed (SEIR) model to capture the dynamic behavior of outbreaks on a regional level [8] and to model possible trajectories of Covid-19 infections and the effects of non-pharmaceutical interventions in the United States [9]. Due to system dynamics' flexibility and simplicity, this study will develop a dynamic system modeling based on a model designed by Tom Fiddaman to evaluate Surabaya City Government's various policies.

\section{METHODS}

\section{A. Dynamic System Simulation}

The research method for developing initial models and policy scenarios is a dynamic system-based simulation with Vensim Ventana software. Dynamic systems simulation is a methodology used to transform actual phenomena into more explicit models whose systems will change over time. This dynamic system is used to avoid using insufficient mental models to construct and translate dynamic models from time to time in a complex system. The model concept is built on the mental Covid-19 pandemic model, adopting a model designed by Tom Fiddaman in 2020 (referred to as the basic model), and then is modified according to conditions in the city of Surabaya [10]. The modification process is carried out by sorting and describing each variable in the Causal Loop Diagram (CLD) and Stock and Flow Diagram (SFD). CLD have been used for purposes connected with simulation modeling and to describe the causal mechanism hypothesized to underlie the reference mode of behavior over time since SFD is useful to clarify the ambiguity and lack of detail in CLD [11]. These two tools were chosen so that the 
modification of the basic model to the initial detailed model was in accordance with the real situation in Surabaya.

\section{B. Data Collection and Processing}

There are three types of data collection and processing, namely mental, written, and numerical data. Mental data were collected from various research sources, which were then processed as a basis for the concept formation of the Covid-19 pandemic in Surabaya. Written and numeric data are used to find the parameter values of each variable. Data collection and processing are adjusted to the needs of each variable in the initial model. The data for designing the initial model is data in the range of the initial period of Covid-19 entering the City of Surabaya to July $31^{\text {st }}, 2020$.

\section{Initial Model Design}

The initial model design was carried out by adding additional mathematical model input and inputting parameter values based on Surabaya City-data. After the input is complete, the next step is to simulate it.

\section{Verification and Validation}

The verification process is carried out in three intuitive mechanisms: common sense, thorough documentation, and traceability. If the model can be simulated well, the next step is validation. Validation is done by comparing the simulation results with existing real situations. Comparisons were made during the initial period of the Covid-19 pandemic entering the City of Surabaya, March $17^{\text {th }}$ to November $9^{\text {th }}, 2020$. This comparison was carried out with two formulas of dynamic system validation tests, namely mean comparison and percentage error variance.

\section{1) Mean Comparison}

A model will be considered valid on the mean comparison test if the value of $\mathrm{E} 1<=5 \%$.

$$
E 1=\frac{|\bar{S}-\bar{A}|}{\bar{A}}
$$

$\bar{S}=$ the average value of the simulation results

$\bar{A}=$ mean value of original data [3].

\section{2) Percentage Error Variance}

A model will be considered valid on the test of the percentage error variance if the value of $\mathrm{E} 2<=30 \%$.

$$
E 2=\frac{|S s-S a|}{S a}
$$

Ss $=$ standard deviation of simulation results $\mathrm{Sa}=$ standard deviation of original data [12].

\section{E. Policy Scenario Design}

Policy scenarios are designed based on policies that have been implemented before and will be implemented in the future but are still not fully implemented. Every policy implemented until July $31^{\text {st }}, 2020$, in the initial model coupled with a policy plan implemented by the Surabaya City Government is included in the model then simulated. The simulation results show various predictions that can be used as an evaluation material for each scenario. This study developed four scenarios, namely herd immunity, implementation of convalescent plasma therapy (TPK), increased swab test, and combination of TPK-increased swab test.

\section{RESUlTS AND DISCUSSIONS}

This chapter will discuss in detail the development of initial models and policy scenarios with dynamic system simulations.

\section{A. Conceptualization of the Model}

The conceptualization of the model begins by adopting the basic model designed by Tom Fiddaman. In the basic model, we implement the SEIR concept outline that describes the Covid-19 pandemic. Susceptible is a healthy population but has a chance of being infected with Covid-19. Exposed is a population that is infected but has not felt any symptoms/symptoms that are mild. Infected is a population that is confirmed by Covid-19. Removed is divided into two, namely recovered, which means the population that has recovered from Covid-19, and deaths mean the population that died because of Covid-19. The basic model can be seen in Fig. 1.

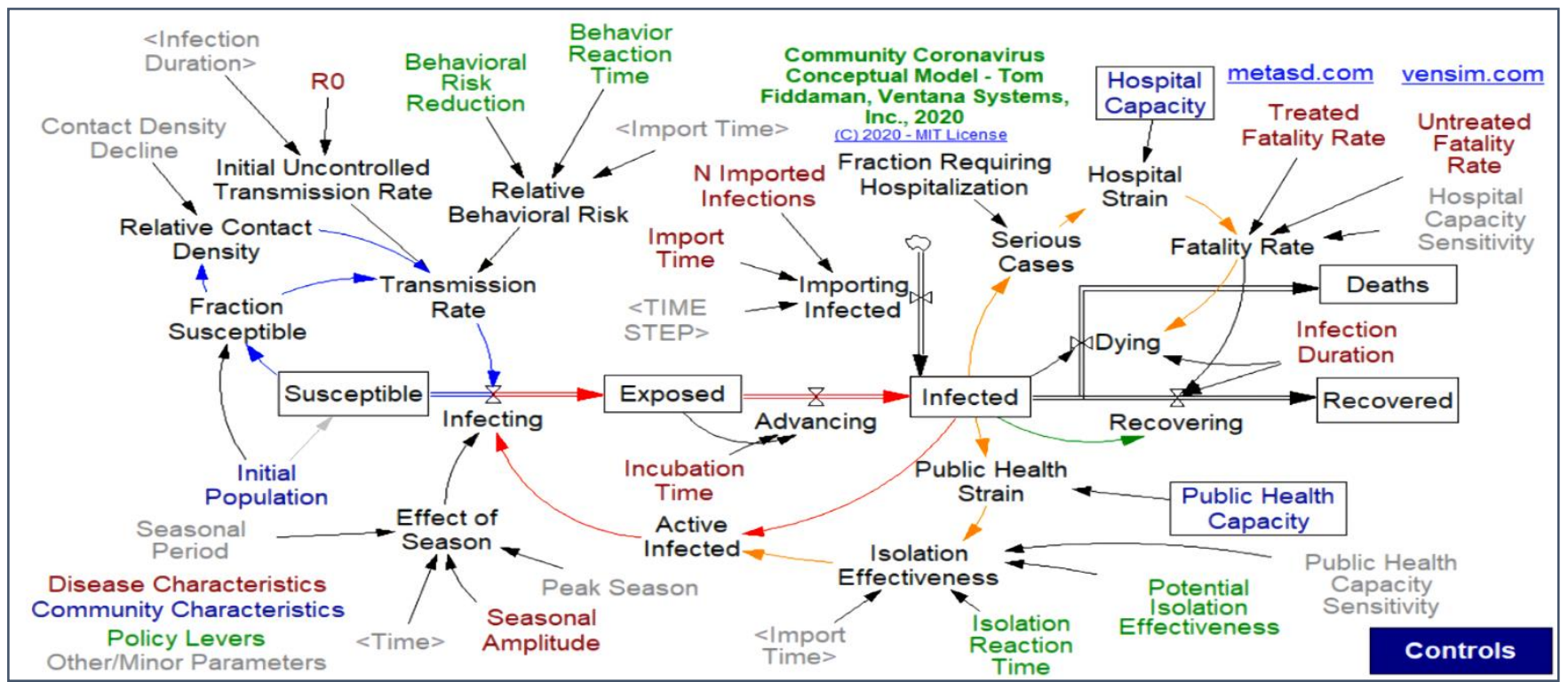

Fig. 1. Basic Model. 
Three big loops make up the Covid-19 pandemic model. First, the loop of infection is synonymous with the term reinforcing loop because, over time, this loop increases the number of infected people. Second, the loop between susceptible people and the rate of infection. This loop is influenced by government intervention, so it acts as a balancing loop. Third, the loop is related to removal. In this loop, there is a reduction in people infected due to cure/death. People who recover are assumed to have a good immune system against Covid-19, so this loop acts as a balancing loop. Because it is adopting, a search was carried out on the suitability of the model composing variables with the real situation of Surabaya City. In the CLD tracing, several variables under modification and their polarity relationship can be seen. The type of variable is detected in SFD. Several variables are categorized into levels, rate, auxiliary, and constant.

\section{B. Initial model}

The initial model was designed to obtain a model representation in accordance with the real situation of Surabaya. The data is collected and processed according to each variable's needs after the model concept is complete. For example, the value of the behavioral risk reduction (BRR) parameter represents a reduction in the risk of transmission due to various government policies. Data collection was carried out on all policy data for March to July 2020 then processed until the BRR parameter values were obtained. Likewise for other parameter values. After the parameter values are obtained, input, adjustment of the outer variables, and the mathematical model's formulation are carried out to obtain the initial model.

1) Initial Model 1: Initial model 1 was simulated for 1,000 days. The graph of the simulation results for the four main variables can be seen in Fig. 2.

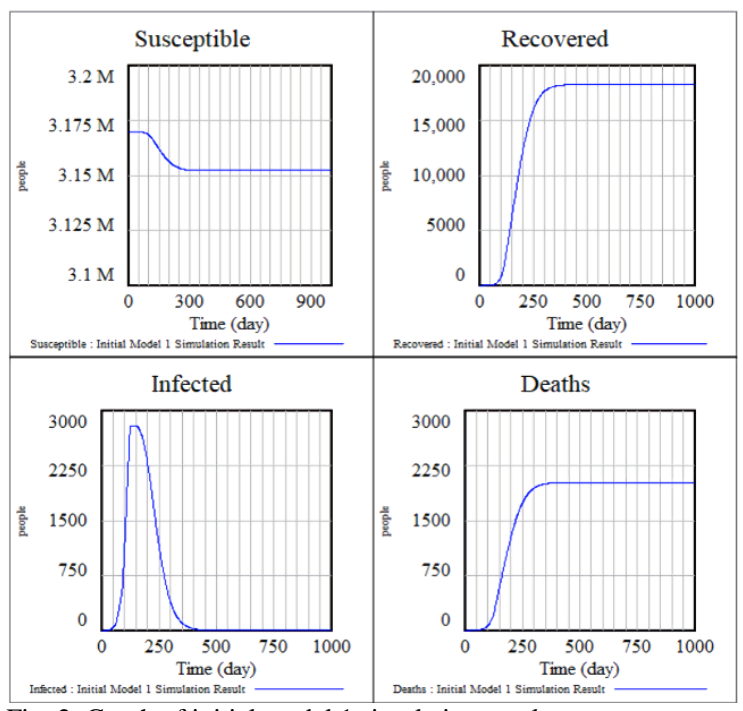

Fig. 2. Graph of initial model 1 simulation results.
Based on Figure 2, it can be analyzed that the infection period occurred for 488 days. The total number of infected cases was 20,278 , of which 18,258 people recovered and 2019 people died. The results of the mean comparison and percentage error variance method validation can be seen in Table 1 . The three variables in the validation test of table 1 using the mean comparison method have a value of $>5 \%$. Furthermore, the variable deaths in the validation test using the percentage error variance method had a value of $>30 \%$, so it was not yet valid. Therefore, the error value must be reanalyzed. The analysis starts from looking at the comparison chart of the difference between the original data and the simulation results in initial model 1. The comparison graph can be seen in Fig. 3 .

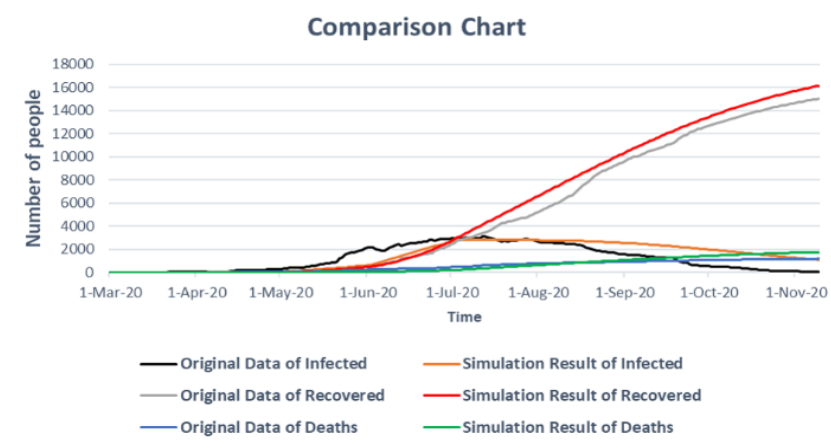

Fig. 3. Comparison chart.

Based on Figure 3, it can be seen that the most significant error is located at the end of July 2020 to November 2020. The original data infected has decreased drastically starting around July 2020. The decline in infected from the simulation results could not offset the instability in this drastic decline. This drastic decrease is the cause of the enormous error value making the model invalid. Based on the recovered variable comparison chart, the recovery rate in the original data increased drastically in the range of July to November 2020. Even the recovered curve in the original data almost catches up with the recovered curve of the simulation results. Even though when compared with the previous discussion, the simulation result of the infected curve is much higher than the infected curve in the original data. Based on the graph of the comparison of the variable deaths, it can be seen that the original data curve for deaths is more sloping than the simulation results. This relates to errors in the infected and recovered variables. Therefore, it can be concluded that the logic might occur is that in July November 2020, there will be a new policy that significantly affects the reduction of cases and an increase in cures but has not been detected because of the last input data until July 2020 only.

Based on the analysis carried out, it was found that starting in July 2020; the Surabaya City Government was intensively implementing TPK [13]. TPK is carried out by donating blood plasma of people who have recovered from Covid-19 to infected people. Starting August 2020,

TABLE I.

VALIDATION OF INITIAL MODEL 1

\begin{tabular}{|c|c|c|c|c|c|c|c|c|}
\hline \multirow{2}{*}{$\begin{array}{c}\text { Variable } \\
\text { Name }\end{array}$} & \multicolumn{4}{|c|}{ Mean Comparison } & \multicolumn{5}{c|}{ Percentage Error Variance } \\
\cline { 2 - 10 } & Original Data & Simulation Result & $\mathrm{E} 1$ & Status & Original Data & Simulation Result & E2 & Status \\
\hline Infected & 1128.147 & 1368.095 & $21.269 \%$ & Invalid & 1114.267 & 1074.317 & $3.585 \%$ & Valid \\
\hline Recovered & 5869.106 & 6266.322 & $6.767 \%$ & Invalid & 6134.864 & 6437.581 & $4.934 \%$ & Valid \\
\hline Deaths & 586.787 & 654.105 & $11.472 \%$ & Invalid & 475.886 & 700.281 & $47.153 \%$ & Invalid \\
\hline
\end{tabular}




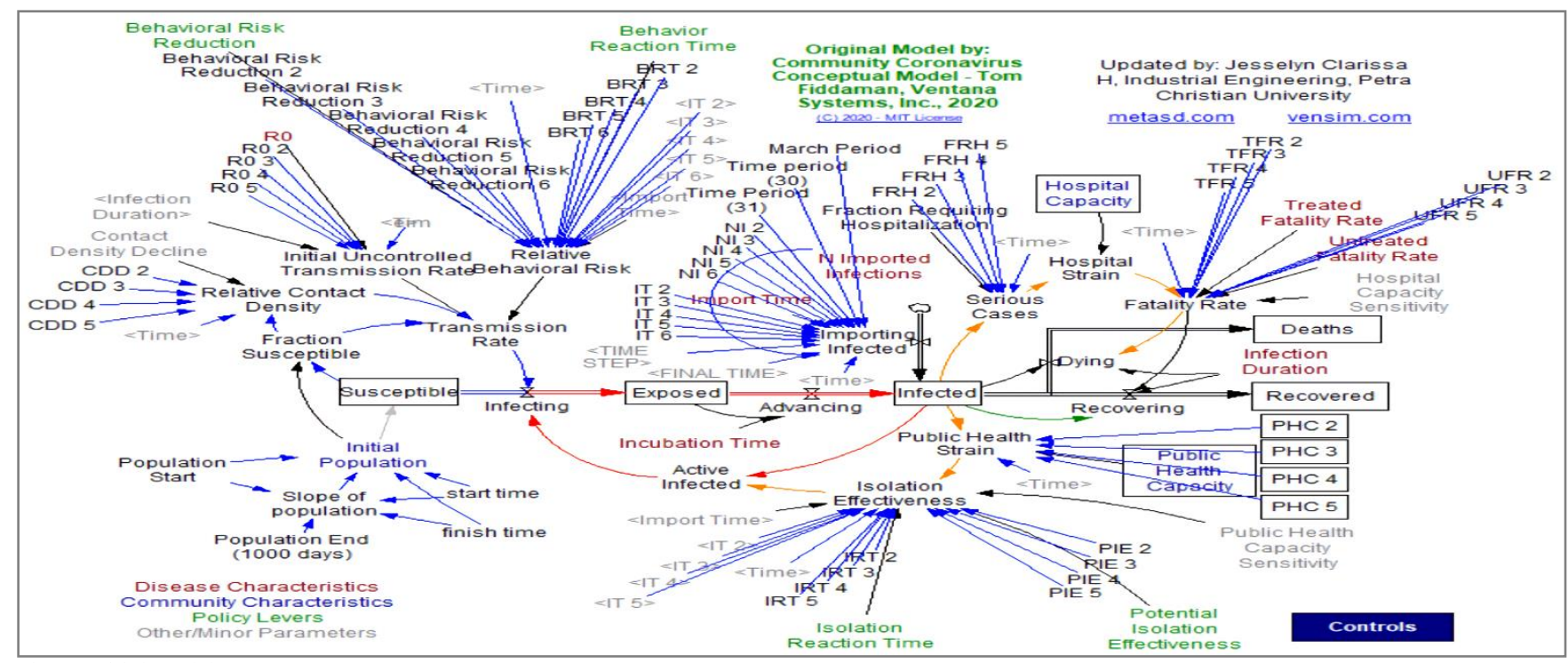

Fig. 4. Initial model 2.

the City of Surabaya has implemented a policy of increasingthe capacity of massive swab tests at Labkesda up to 4,000 samples/day. The increase in capacity is then assumed to be followed by an increase in daily massive swab tests intensively carried out by the Surabaya City Government [14]. However, after tracing Surabaya City's data, it turned out that the policy of increasing the swab test had not been followed by public enthusiasm so that the swab tests carried out at Labkesda were around 2,225 samples from 2,000 samples previously. Parameter values that have changed are the treated fatality rate (TFR), untreated fatality rate (UFR), and potential isolation effectiveness (PIE), R0, behavioral risk reduction (BRR), $\mathrm{N}$ imported infections (NII), and fraction requiring hospitalization (FRH). The design of the previous model was adapted to changes due to additional policies. Initial model 2 can be seen in Fig. 4.

2) Initial Model 2: Initial model 2 was simulated for 1,000 days. After the parameter value changes and adjustments are made, the next step is to simulate. When the simulation is carried out, the model can run in a relevant way to properly verify the model. Figure 5 describes that the period of infection occurred for 413 days. During the infection period, it was predicted that the total number of infected cases was 15,875 people, of which 14,456 people recovered and 1,418 people died. Table 2 shows the simulation validation results using the mean comparison and percentage error variance method. Based on Table 2, the three variables in the validation test using the mean comparison method have a value of $<5 \%$. Furthermore, the three variables in the validation test using the percentage error variance method have a value of $<30 \%$. The validation test results using both methods are declared valid and can be used as a reference model for policy scenario design.

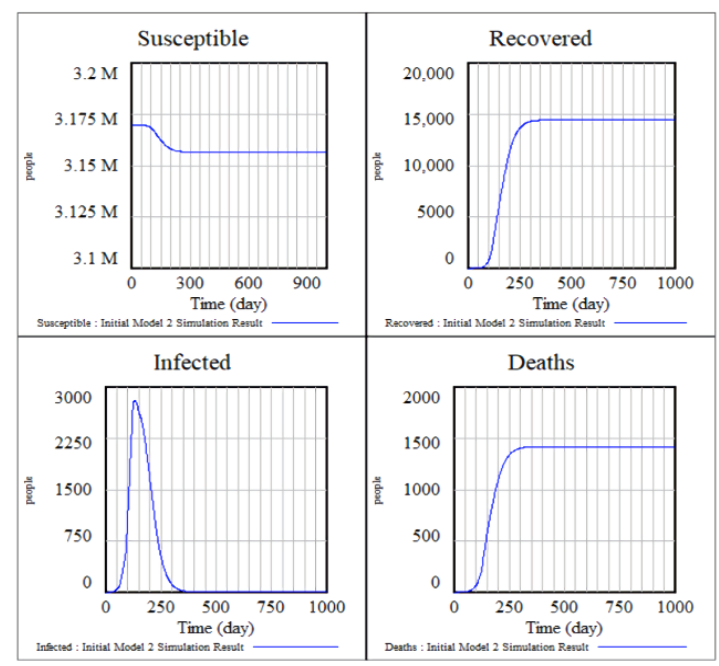

Fig. 5. Graph of initial model 2 simulation results.

\section{Scenario}

There are four scenarios built in this study.

1) Scenario 1: Herd Immunity

Herd immunity is the absence of any intervention from the government during the pandemic. The scenario concept is to build five types of models based on a reference of five months of data. If implemented from April 2020, there will still be an intervention in March 2020. Changes in parameter values are carried out with three main concepts, namely BRR and PIE, and RO. BRR and PIE are assumed to be 0 since there was no intervention. R0 is assumed to be a max of 4 after the policy is enforced. For NII, FRH, TFR, UFR, and public health capacity (PHC) is kept constant the following month. The simulation results can be seen in Fig. 6. Based on Figure 6, of the five models, the fastest peak pandemic results will be achieved if the implementation of herd immunity is implemented in March 2020. However, the peak of the infected population and the end of the smallest

TABLE II. VALIDATION OF INITIAL MODEL 2

\begin{tabular}{|c|c|c|c|c|c|c|c|c|}
\hline \multirow{2}{*}{$\begin{array}{c}\text { Variable } \\
\text { Name }\end{array}$} & \multicolumn{4}{|c|}{ Mean Comparison } & \multicolumn{4}{c|}{ Percentage Error Variance } \\
\cline { 2 - 9 } & Original Data & Simulation Result & E1 & Status & Original Data & Simulation Result & E2 & Status \\
\hline Infected & 1128.147 & 1138.965 & $0.934 \%$ & Valid & 1114.267 & 1016.082 & $8.786 \%$ & Valid \\
\hline Recovered & 5869.106 & 5853.998 & $0.271 \%$ & Valid & 6134.864 & 5795.466 & $5.518 \%$ & Valid \\
\hline Deaths & 586.787 & 561.784 & $4.307 \%$ & Valid & 475.886 & 568.903 & $19.645 \%$ & Valid \\
\hline
\end{tabular}


pandemic is achieved when herd immunity was implemented in July 2020. Herd immunity is not the best policy that should be implemented because from the five models, and the total infected population is around $+/-90 \%$ of the population.

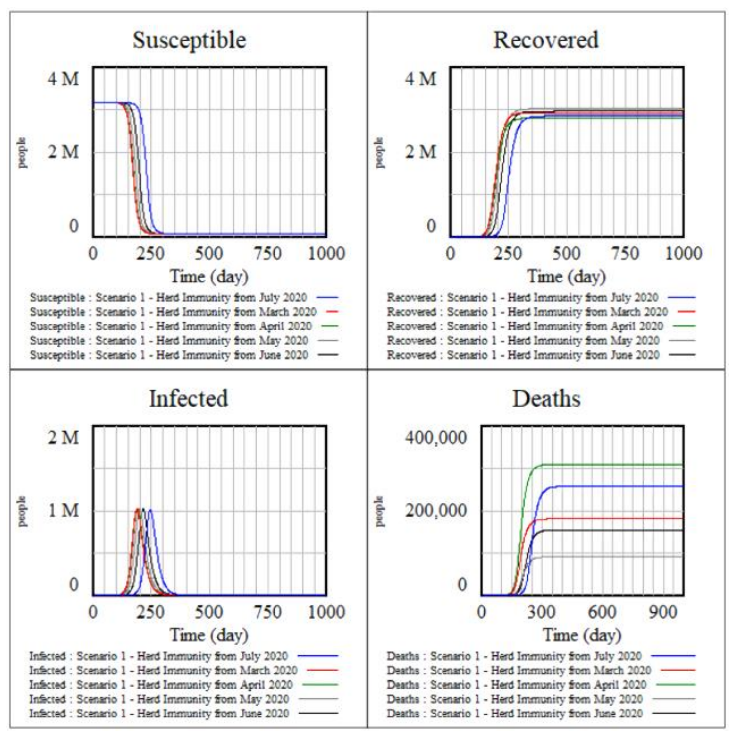

Fig. 6. Graph of scenario 1 simulation results.

2) Scenario 2: Convalescent plasma therapy

TPK is built to predict the pandemic situation in Surabaya in the future when the TPK policy was implemented in July 2020. Changes in parameter values were made for R0, BRR, NII, FRH, TFR, UFR, and PIE. The simulation results of scenario 2 are in Fig. 7.

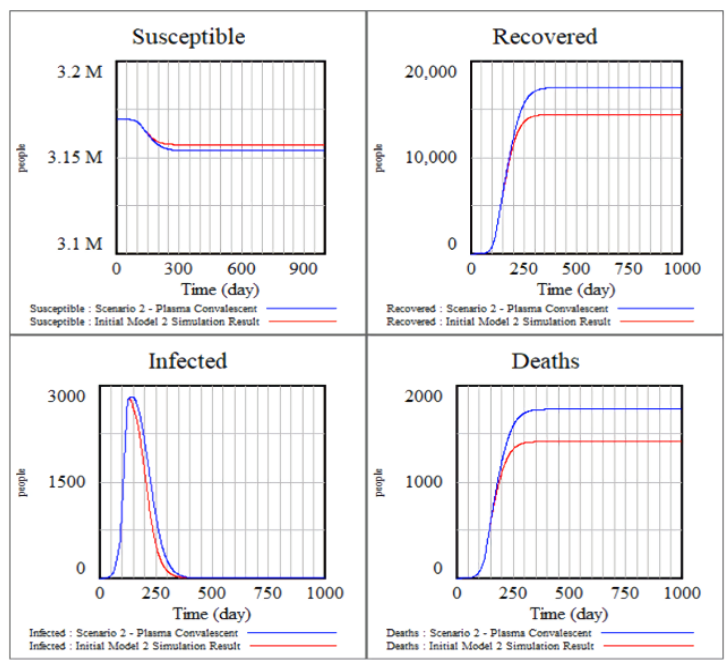

Fig. 7. Graph of scenario 2 simulation results.

\section{3) Scenario 3: Swab test increase}

The increase in swab tests is implemented based on the failure to achieve the initial plan of the Surabaya City Government to increase the swab test to 4,000 samples. This scenario was built to predict the pandemic situation in Surabaya for the future if the policy was added to increase the swab test up to 4,000 samples/day without TPK. The concept of the scenario is that the swab test policy was implemented in August 2020. The scenario is designed to increase the swab test up to 4,000, 3,000, and 2,500 samples/day. Changes in parameter values were made for the variables R0, BRR, NII, and FRH. After all changes in parameter values are inputted, simulation is carried out. The simulation results can be seen in Fig. 8.

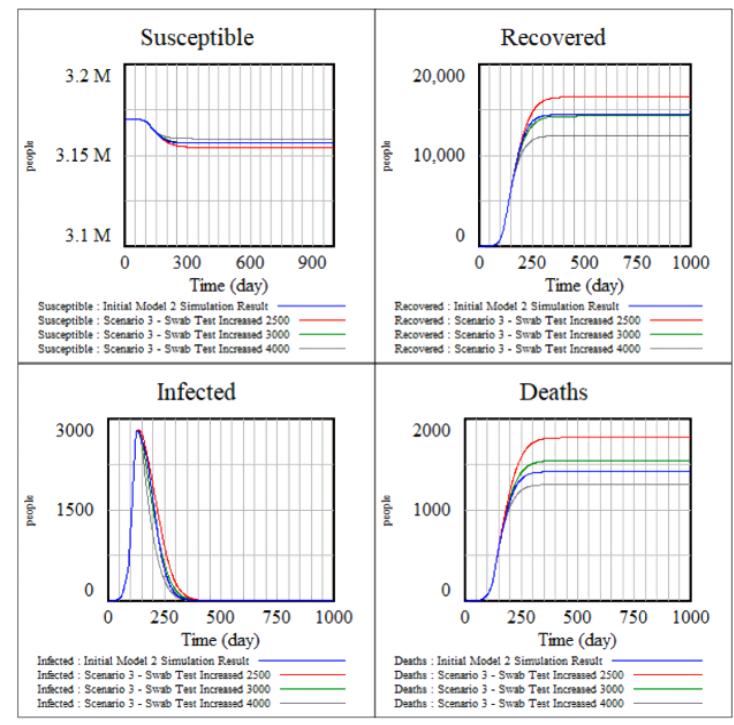

Fig. 8. Graph of scenario 3 simulation results.

4) Scenario 4: Combined convalescent plasma therapy and swab test increase

This scenario was built to determine the prediction of a pandemic situation if the TPK policy was added and the swab test increased to 4,000 samples/day. The scenario concept is that the TPK policy was implemented in July 2020, while the swab test was implemented in August 2020. The scenario is designed to increase the swab test at Labkesda up to 4,000; 3,000; and 2,500 samples/day. Changes in parameter values were carried out for R0, BRR, NII, FRH, TFR, UFR, and PIE. After all changes in parameter values are entered, they are simulated. The simulation results of scenario 4 can be seen in Fig. 9.

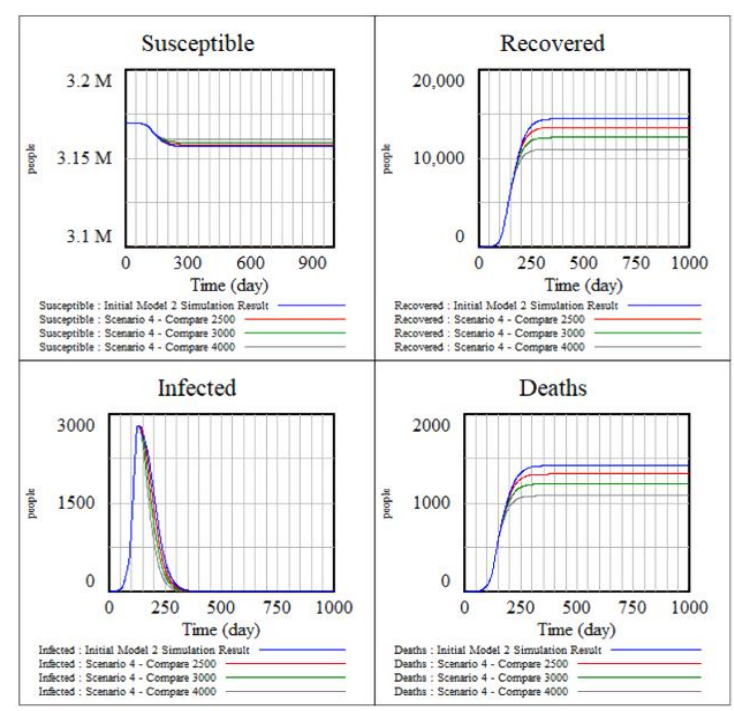

Fig. 9. Graph of scenario 4 simulation results.

Fig. 9 describes the pandemic's fastest peak, and the end was achieved in the combined TPK and an increase of 4,000 Swab test. It predicts the end of the pandemic on March 14, 2021. The three models in this combined scenario show better results than the initial model. This proves that the collaboration between increasing swab tests and TPK is the best policy in this study to overcome the Covid-19 pandemic in Surabaya. The more vigorous swab tests and TPK are carried out, the sooner the pandemic will end. 


\section{Comparison between policy scenarios}

Scenario 1-herd immunity is not the best policy since the total infected population can reach $+/-90 \%$ of the population. Also, even though the herd immunity policy scenario is carried out as early as March 2020, the prediction for the end of the pandemic is still very long, July $19^{\text {th }}, 2021$. In scenario 2, the prediction results for the end of the pandemic on June $7^{\text {th }}, 2021,33$ days are longer than the initial model. The total population infected was $19.77 \%$ larger than the initial model. In scenario 3, the end of the pandemic's prediction results in a row for an increase in 4,000 ; 3,000; and 2,500 are April 30 ${ }^{\text {th }}, 2021$, June $4^{\text {th }}, 2021$, and July $1^{\text {st }}, 2021$. The infection period is five days faster for 4,000, while for 3,000 and 2,500, the infection period occurred 30 and 57 days longer than the original model. The total infected population for the increase of 4,000;3,000; and 2,500 was $15.48 \%$ was less for 4,$000 ; 0.320 \%$ less for 3,000 ; and $14.62 \%$ less for 2,500 .

Although scenario 3,000 had a smaller percentage of infections than the initial model but had a much more extended infection period than the initial model. Therefore, if this scenario is carried out individually, the results are worse than the initial model. Scenario 3 is just said to be better than the initial model if increasing 4,000 samples are continuously achieved every day. In scenario 4 , the end of the pandemic's prediction results in a row for an increase in 4,000; 3,000; and 2,500 are March $14^{\text {th }}, 2021$, April $4^{\text {th }}, 2021$, and July $19^{\text {th }}, 2021$. The infection period consecutively is 52 days, 31 days, and 16 days from the initial model infection period. The total infected population for the increases of 4,000 ; 3,000 ; and 2,500 was $23.77 \%$ less for 4,$000 ; 14.58 \%$ less for 3,000 ; and $6.63 \%$ less for 2,500 than early models. The impact of hospital needs is represented by the hospital strain variable, while the impact of the need for isolation space is represented by the public health strain variable, both of which can be seen in Table III.

TABLE III. IMPACT OF THE HOSPITAL AND PUBLIC HEALTH NEEDS

\begin{tabular}{|c|c|c|c|}
\hline \multirow{2}{*}{ Scenario } & $\begin{array}{c}\text { Model } \\
\text { Type }\end{array}$ & $\begin{array}{c}\text { Hospital Needs } \\
\text { (times from capacity) }\end{array}$ & $\begin{array}{c}\text { Public Health Needs } \\
\text { (times from capacity) }\end{array}$ \\
\hline \multirow{4}{*}{$\begin{array}{c}\text { Herd } \\
\text { Immmity }\end{array}$} & March 2020 & 219.565 & 0.7502 \\
\cline { 2 - 4 } & April 2020 & 219.543 & 0.7501 \\
\cline { 2 - 4 } & May 2020 & 568.073 & 0.7499 \\
\cline { 2 - 4 } & June 2020 & 178.141 & 0.7489 \\
\cline { 2 - 4 } & July 2020 & 205.059 & 0.7440 \\
\hline TPK & - & 0.564 & 0.00208 \\
\hline \multirow{2}{*}{$\begin{array}{c}\text { Increased } \\
\text { Swab Test }\end{array}$} & 4000 & 0.773 & 0.002060 \\
\cline { 2 - 4 } & 3000 & 0.675 & 0.002063 \\
\hline Combined & 2500 & 0.630 & 0.002072 \\
\cline { 2 - 4 } TPK and & 4000 & 1.212 & 0.002059 \\
\cline { 2 - 4 } Swab Test & 3000 & 1.149 & 0.002062 \\
\cline { 2 - 4 } & 2500 & 1.126 & 0.002065 \\
\hline
\end{tabular}

\section{CONCLUSION}

The Covid-19 pandemic has become increasingly rampant in the city of Surabaya. To determine municipal government policies to be right on target, policy scenarios are simulated first with a dynamic system simulation. The herd immunity scenario was concluded as the worst-case scenario. The prediction for the end of the pandemic is still very long, 75 days longer than the initial model. The total population infected is 195 times larger than the initial model. For TPK policy, the prediction for the end of the pandemic is
33 days longer than the initial model with total population infected $19.77 \%$ greater than the initial model. By increasing the swab test of up to 4,000 samples every day, the simulation result is better than the initial model. This achievement resulted in predicting the percentage of the infected population being $15.48 \%$ smaller and with an infection period of 5 days faster than the results of the initial model simulation. A prediction for the end of the pandemic is obtained 52 days faster than the initial model when the government combined TPK policy with increase number of swab test patient. The percentage of the population infected was $23.77 \%$ smaller than the initial model. Therefore, the Government's strategy by collaborating with the swab test and TPK policies is useful for dealing with the Covid-19 pandemic in Surabaya City. However, for policies to be implemented properly, contributions from all society elements are required since the more incessant swab tests and TPK are carried out, the sooner the pandemic will end.

\section{REFERENCES}

[1] Gugus Tugas Percepatan Penanganan Covid-19. (2020). Peta Sebaran. Retrieved July 17, 2020, from https://covid19.go.id/petasebaran.

[2] Batchelder, A.W., Gonzalez, J.S., Palma, A., Schoenbaum, E., Lounsbury, D.W. (2015) A social ecological model of syndemic risk affecting women with and at-risk for HIV in impoverished urban communities. Am. J. Community Psycol, 56, 220-240.

[3] Weeks, M.R., et al. (2017) Using participatory system dynamics modeling to examine the local HIV test and treatment care continuum in order to reduce community viral load. Am. J. Community Psycol, 60, 584-598.

[4] Sihombing, L., et al. (2020, May 9). An Analysis of the Spread of COVID-19 and its Effects on Indonesia'S Economy: A Dynamic Simulation Estimation. May. Available http://dx.doi.org/10.2139/ssrn.3597004

[5] Kozlovskyi, S., et al. (2020). The system dynamic model of the labor migrant policy in economic growth affected by COVID-19. Global Journal of Environmental Science and Management, 6 (Special Issue (Covid-19)), 95-106.

[6] Niwa, M., Hara, Y., Sengoku, S., Kodama, K. (2020). Effectiveness of Social Measures against COVID-19 Outbreaks in Selected Japanese Regions Analyzed by System Dynamic Modeling, Int. J. Environ. Res. Public Health 17, no. 17: 6238.

[7] Cooper, I., Mondal, A., Antonopoulos, C.G. (2020). Dynamic tracking with model-based forecasting for the spread of the COVID19 pandemic. ScienceDirect: Chaos, Solitons \& Fractals. Volume 139, October 2020, 110298.

[8] Engbert, R., Rabe, M. M., Kliegl, R., \& Reich, S. (2020, December). Sequential Data Assimilation of the Stochastic SEIR Epidemic Model for Regional COVID-19 Dynamics. Springer Link. Bull Math Biol 83, 1. https://doi.org/10.1007/s11538-020-00834-8

[9] Hay, Simon I. (2020). Modeling COVID-19 scenarios for the United States. Nature Medicine, volume 27, pages94-105.

[10] Fiddaman, T. (2020, March 11). Coronavirus \& Epidemic Modeling. Retrieved July 17, 2020, from https://vensim.com/coronavirus/

[11] Sterman, J. D. (2000). Business Dynamics Systems: Thinking and modeling for a complex word. McGraw-Hill.

[12] Satrio, P. \& Suryani, E. (2017). Penerapan model sistem dinamik untuk melakukan pemeliharaan operasional aset unit transmisi dan visualisasi luaran model dengan menggunakan dashboard (Studi kasus: PT. PLN (Persero) App Semarang). Jurnal Teknik ITS, 6, A327-A332. Retrieved from https://core.ac.uk/download/pdf/289794189.pdf

[13] Sumarno, J. T. (2020, June 30). PMI Layani Donor Plasma Konvalesen Warga Kota Surabaya. SuaraSurabaya.net. Retrieved from https://www. suaraSurabaya.net/kelanakota/2020/pmi-layanidonor-plasma-konvalesen-warga-kota-Surabaya/

[14] Ginanjar, D. (2020, September 16). Dalam Sehari Labkesda Surabaya Bisa Uji 4000 Sampel Covid-19. JawaPos.com. Retrieved from https://www.jawapos.com/Surabaya/16/09/2020/dalam-sehariLabkesda-Surabaya-bisa-uji-4-000-sampel-Covid-19 